\title{
SISTEM INFORMASI TUGAS AKHIR MAHASISWA PADA PROGRAM STUDI STMIK PALANGKARAYA BERBASIS WEB MOBILE
}

\author{
Susi Hendartie \\ Program Studi Sistem Informasi STMIK Palangkaraya \\ Jalan G.Obos No. 114 Palangka Raya \\ Email : susihendartie@gmail.com
}

Information systems and computer technology was developing rapidly because for information needed. The development of information technology. Could not separated from develop of computer technology, because computer was a media that could make easy to finish their work. The Change and dynamics of society's grown rapidly with developmen of information technology that requires effective and efficient in terms of time. One of them helped in the process of final exam. The writer interest to make an information system based on mobile web that can solve the problem. The system will make based on object with the title make a data of final exam information system in Faculty of STMIK Palangkaraya based on mobile web.

The results of this study are expected by the online aplication Final exam in faculty of STMIK Palangkaraya final and students to sign the final task quikly and accurately to assisted help faculty STMIK of Palangkaraya to collected a data of final exam and for student to sign. Final exam Seminar proposal, Final task quikkly and accurately. The collection of data by used this aplication also does not consume a lot of time and money because it can reach Final registration which is outside the city, outside the island even residing outside the country though.

\section{Keyword : Information System, final exam}

\section{PENDAHULUAN}

Di Era sekarang ini perkembangan teknologi informasi dalam segala aspek mendorong perguran tinggi untuk melakukan langkah-langkah strategis agar bisa tetap unggul dalam segala bidang. Peran teknologi informasi pada perguruan tinggi mulai bisa dirasakan dalam kegiatan/proses akademik. Beberapa perguruan tinggi baik swasta atau pun negeri sudah memanfaatkan sistem informasi yang merupakan bagian dari teknologi informasi.

Sekolah Tinggi Manajemen Informatika dan Komputer (STMIK) Palangkaraya adalah salah satu perguruan tinggi pertama di Provinsi Kalimantan Tengah yang bergerak di bidang teknologi informasi dan ilmu komputer. Sebagai perguruan tinggi swasta STMIK Palangkaraya berusaha terus untuk meningkatkan pendidikan bagi mahasiswa yang menempuh pendidikan dibidang IT.

Pengajuan Tugas Akhir mahasiswa pada STMIK Palangkaraya masih menggunakan sistem yang konvensional. Dalam pendaftar judul untuk tugas akhir, seminar proposal dan Ujian Skripsi mahasiswa diwajibkan mengisi formulir yang kemudian diarsipkan dan datadata tersebut diketik kembali menggunakan
Microsoft Word, sedangkan informasi yang berkaitan dengan judul tugas akhir mahasiswa yang diterima, daftar dosen pembimbing tugas akhir, jadwal seminar proposal dan jadwal ujian skripsi menggunakan papan pengumuman yang disediakan pada masing-masing Program Studi.

Sebagaimana hal diatas mengingat begitu pentingnya penggunaan teknologi bagi STMIK Palangkaraya maka dalam pengelolaan Tugas Akhir Mahasiswa perlu dibangun suatu sistem informasi berbasis Web Mobile yang mampu menangani permasalahan yang ada. Sehingga dapat memudahkan program studi pada STMIK Palangkaraya menyebarkan informasinya secara cepat dan dapat diakses oleh mahasiswa kapanpun dan dimana saja.

\section{LANDASAN TEORI}

1. Sistem Informasi

Menurut Jogiyanto (2009:11) sistem informasi adalah suatu sistem dalam suatu organisasi yang mempertemukan kebutuhan pengolahan transaksi harian mendukung operasi, bersifat manajerial dan kegiatan strategi dari suatu organisasi dan menyediakan pihak luar tertentu dengan laporan-laporan yang diperlukan. 


$$
\begin{array}{r|l}
\text { Jurnal Sains Komputer dan Teknologi Informasi } & \text { Page } \\
\text { e-issn: 2655-7460. Volume i No.2, Mei 2019 } & 31-37
\end{array}
$$

\section{Web Mobile}

Menurut Andi (2013:3) Web Mobile Adalah sama dengan website secara umum, yang dibuat dengan HTML, CSS, javascript, $P H P$. Namun perbedaannya adalah mobile website dibuat agar optimal untuk ukuran layar mobile device seperti smartphone atau tablet.

3. jQuery

Menurut Wahana Komputer (2013:2) jQuery adalah sebuah framework berbasis JavaScript. jQuery sama dengan JavaScript Library, yaitu kumpulan kode atau fungsi. JavaScript siap pakai sehingga mempermudah dan mempercepat dalam membuat kode JavaScript.

\section{4. $\quad$ Twiter Bootstrap}

Menurut Hafiz Ridha (2007:4) twiter bootstrap adalah sebuah alat bantu untuk membuat sebuah tampilan halaman website yang dapat mempercepat pekerjaan seseorang pengembang website atau[un pendesain halaman website. Sesuai namanya, website yang dibuat dengan alat bantu ini memiliki tampilan halaman yang sama/ mirip dengan halaman Twiter atau desainer juga dapat mengubah tampilan halaman website sesuai dengan kebutuhan.

\section{HTML}

Menurut Arief (2011:23) HTML atau HyperText Markup Language merupakan salah satu format yang digunakan dalam pembuatan dokumen dan aplikasi yang berjalan di halaman web. Dokumen ini dikenal sebagai web page. Dokumen HTML merupakan dokumen yang disajikan pada web browser.

6. $\quad$ PHP (PHP Hypertext Preprocessor)

Menurut Aditya N. A (2011:1) PHP

(PHP Hypertext Preprocessor) adalah bahasa skrip yang dapat ditanamkan atau disisipkan ke dalam HTML. PHP banyak dipakai untuk memprogram situs Web dinamis. PHP dapat digunakan untuk membangun sebuah $C M S$.

\section{JavaScript}

Menurut Wahana Komputer (2010:1) JavaSkript merupakan bahasa yang terbentuk kumpulan skrip yang berfungsi untuk memberikan tampilan yang tampak lebih interaktif pada dokumen web.

JavaScript adalah bahasa pemrograman untuk memberikan kemampuan tambahan kedalam bahasa pemrograman HTML (Hypertext Markup Language) dengan mengijinkan pengeksekusian perintah-perintah pada sisi client, dan bukan sisi server dokumen web. Pada hakikatnya, bahasa pemrograman
JavaScript berisi Skrip yang pemasangannya terselip disebuah dokumen HTML.

JavaScript dan Java memang hampir sama.tidak jarang orang salah konsepsi dalam pengertian kedua bahasa tersebut dan beranggapan bahasa pemrograman Java merupakan bagian dari pemrograman JavaScript.

8. UML(Unified Modelling Language)

Menurut Pressman (2010:987) Unifield

Modeling Language (UML) adalah "bahasa standar untuk penulisan cetak biru perangkat lunak. $U M L$ dapat digunakan untuk memvisualisasikan, menentukan, mengonstruksi, dan mendokumentasikan artifak-artifak suatu sistem software-intensive".

9. XAMPP

Menurut Riyanto (2010:1) XAMPP merupakan paket $P H P$ dan $M y S Q L$ berbasis Open Source, yang dapat digunakan sebagai tool pembantu pengembangan aplikasi berbasis PHP.

\section{ANALISA DAN DESAIN}

1. Analisis Kelemahan Sistem

Langkah-langkah dalam kelemahan sistem hampir sama dengan langkah-langkah yang dilakukan dalam mendefenisikan proyek-proyek sistem ang akan dikembangkan ditahap perencanaan sistem, perbedaannya terletak pada ruang lingkup tugasnya.

a. Identifly, yaitu mengindentifikasi masalah. Pada penelitian ini masalah yang dihadapi oleh STMIK Palangkaraya dengan sistem lama pendaftaran, pengumuman dan berita masih mengunakan cara manual yaitu dengan menempelkan pengumuman pada papan pengumuman pengolahan data pengajuan judul Tugas Akhir masih secara manual dengan mengunakan stofmap.

b. Understand, memahami kerja dari sistem yang ada. Sistem yang sedang berjalan saat ini pada STMIK Palangkaraya adalah pengajuan judul dan pengumuman pada papan pengumuman masih mengunakan cara manual yaitu untuk pendaftaran masih mengunakan stofmap dan diantarkan kejurusan masingmasing, sedangkan pengumuman masih mengunakan papan pengumuman.

c. Analyze, yaitu menganalisis sistem. Analisis sistem dapat didefenisikan sebagai tahap penguraian dari suatu sistem yang dilakukan setelah tahap perencanaan sistem (system palnning) dan sebelum tahap desain sistem (system design). Dalam tahapan analisis memiliki perbedaan dengan tahapan 
Palangkaraya Berbasis Web Mobile

perencanaan, dimana dalam tahapan analisis lingkup tugasnya lebih terperinci. Penulis akan menganalisis bagaimana proses pengajuan Judul dan Pengumuman Tugas Akhir.

d. Report, yaitu membuat laporan akhir dari hasil analisis. Laporan hasil.

2. Desain input

a. Desain Input Pengguna (User) Data Pendaftaran Tugas Akhir

\begin{tabular}{|c|c|c|}
\hline \multicolumn{2}{|c|}{ Pendaftaran Tugas Akhir } & \\
\hline \multicolumn{3}{|r|}{ DATA INPUT } \\
\hline & $\begin{array}{l}\text { - Nim } \\
\text { - Nama } \\
\text { - Email } \\
\text { - No. Hp } \\
\text { - Jurusan } \\
\text { - Perusa } \\
\text { - Judul S } \\
\text { - Pembin } \\
\text { - Pembin } \\
\text { - File Na } \\
\text { - File Pe }\end{array}$ & $\begin{array}{l}\text { aan/Instansi } \\
\text { aripsi } \\
\text { bing } 1 \\
\text { bing } 2 \\
\text { kah Proposal } \\
\text { syaratan Pengajuan Judul }\end{array}$ \\
\hline
\end{tabular}

b. Desain Input Pengguna Data Pendaftaran Seminar Proposal

Pendaftaran Seminar Proposal

$\quad$ DATA INPUT
- Nim
- Nama
- Jurusan
- Pembimbing 1
- Pembimbing 2
- Judul Skripsi
- File Persyaratan Seminar Proposal

c. Desain Input Pengguna Data Pendaftaran Sidang Skripsi

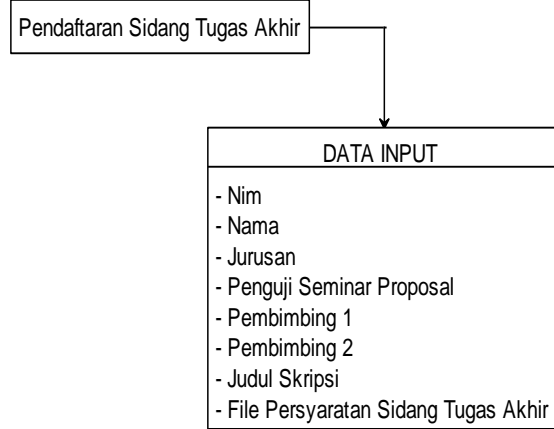

d. Desain Input Admin (Administrator) Login

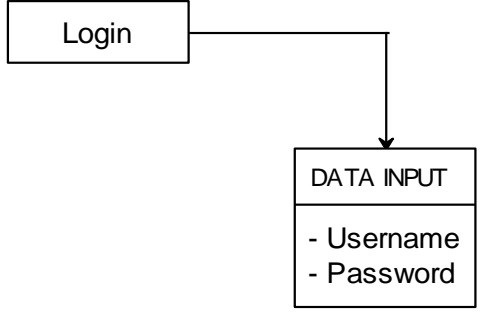

e. Desain Input Admin Ganti Password

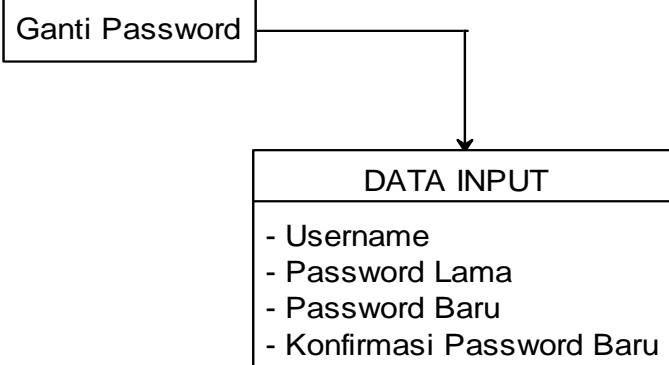

f. Desain Input Admin Data Mahasiswa

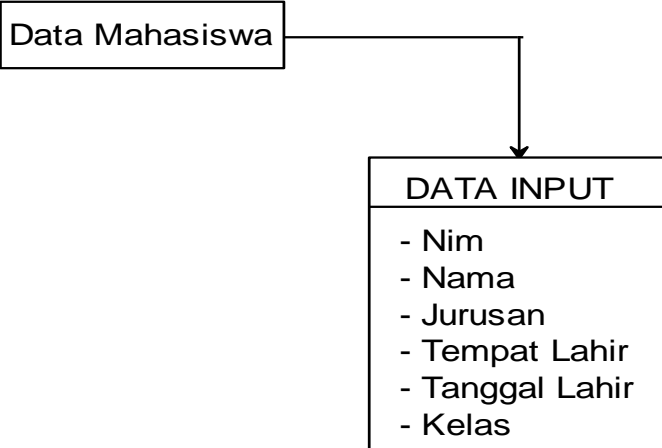

g. Desain Input Admin Data Dosen Pembimbing

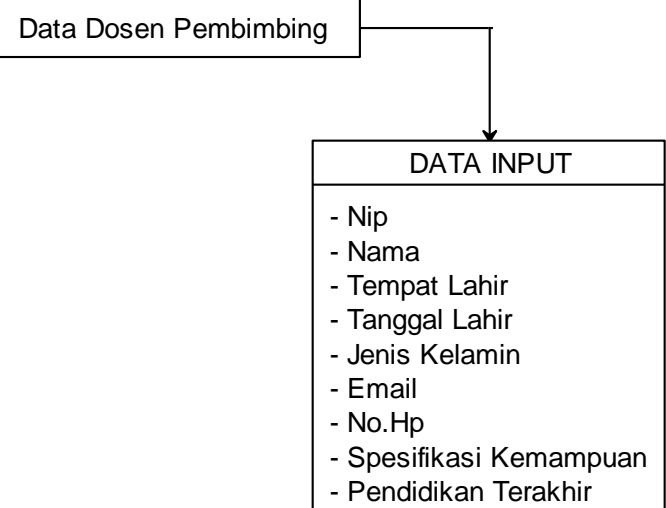




$$
\begin{array}{c|l}
\text { Jurnal Sains Komputer dan Teknologi Informasi } & \text { Page } \\
\text { e-issn: 2655-7460. Volume 1 No.2, Mei 2019 } & 31-37
\end{array}
$$

h. Desain Input Admin Data Pengajuan Judul

\section{Data Pengajuan Judul}

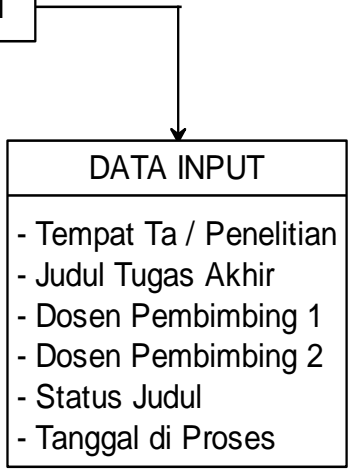

i. Desain Input Admin Data Pendaftaran Seminar

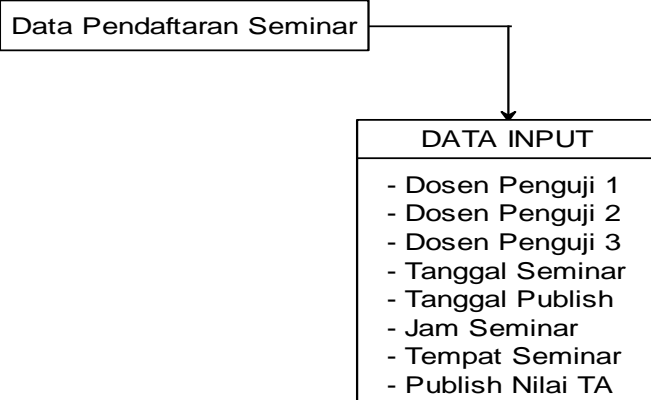

j. Desain Input Admin Data Pendaftaran Sidang

Data Pendaftaran Seminar

\section{DATA INPUT}

- Dosen Penguji 1

- Dosen Penguji 2

- Dosen Penguji 3

- Dosen Penguji 4

- Dosen Penguji 5

- Tanggal Sidang

- Tanggal Publish

- Jam Sidang

- Tempat Sidang

- Publish Jadwal Sidang k. Desain Input Admin Data Nilai Tugas Akhir

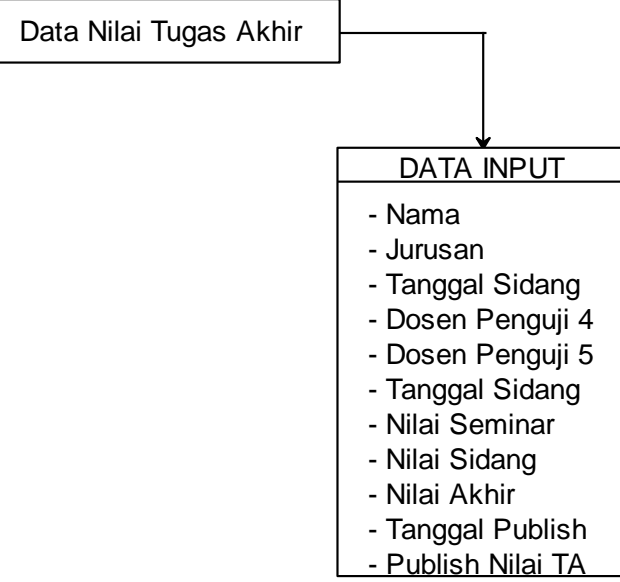

1. Halaman Desain Input Persyaratan Tugas Akhir

Data Persyaratan TA

\begin{tabular}{|l|}
\hline \multicolumn{1}{|c|}{ DATA INPUT } \\
\hline - Jurusan \\
- Isi Persyaratan \\
\hline
\end{tabular}

\section{HASIL DAN PEMBAHASAN}

Hasil dari desain akan di implementasikan kedalam system yang diuraikan sebagai berikut: 1. Menu Login Admin

Pada saat mengakses alamat admin wajib login agar dapat mengelola Sistem Informasi Tugas Akhir Pada STMIK Palangkaraya Berbasis Web.

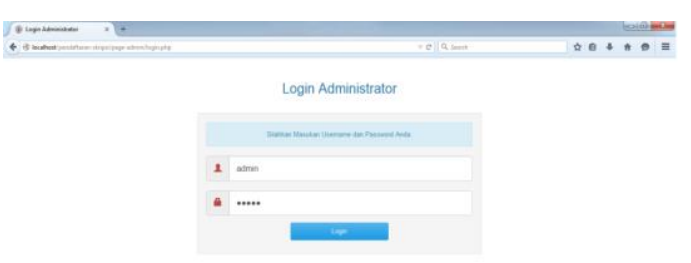

Gambar 1. Menu Login Admin

\section{Halaman Utama Admin}

Setelah berhasil login, tampil halaman utama untuk admin yang mana terdapat menu master yaitu pengajuan judul, pendaftaran seminar, 
Palangkaraya Berbasis Web Mobile

pendaftaran sidang, data mahasiswa, data dosen, data nilai, arsip, persyaratan, dan kritik - saran, kemudian disisi kanan atas terdapat menu change theme/skin dan menu dropdown admin terdapat ubah password dan logout.

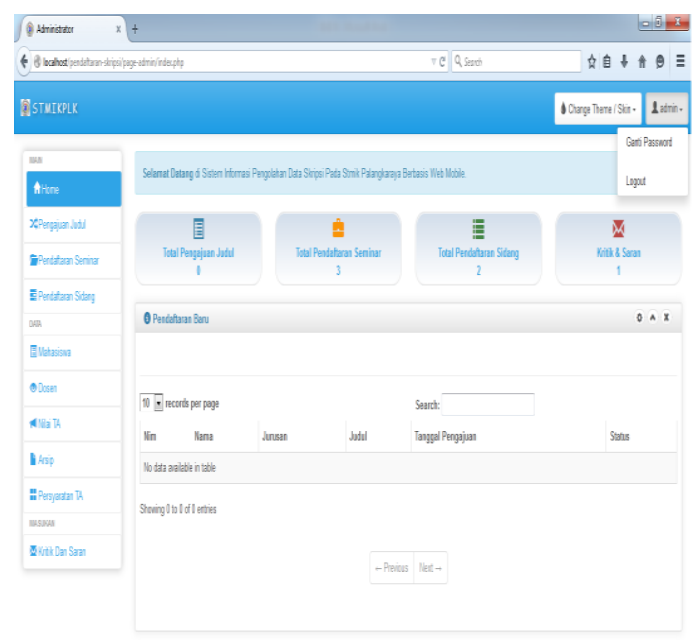

Gambar 2. Halaman Utama Admin

3. Halaman Pengajuan Judul

Apabila memilih menu pengajuan judul maka akan tampil jumlah mahasiswa yang mengajukan judul dan dapat dipilih sesuai jurusan.

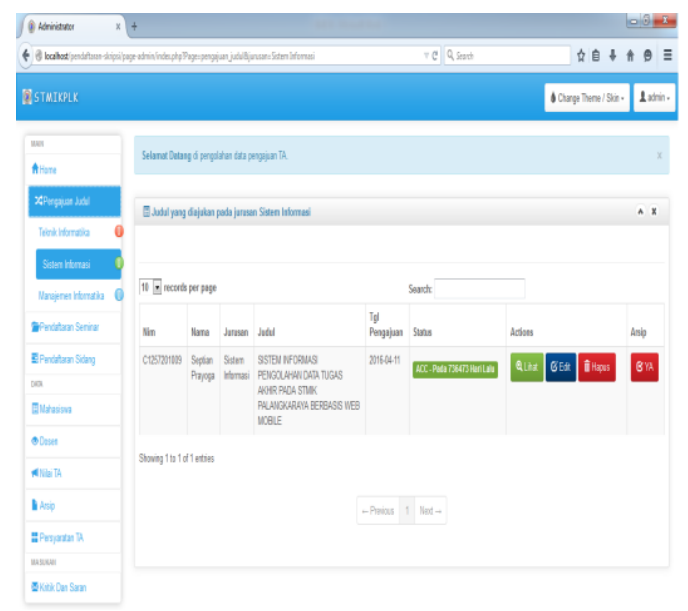

Gambar 3. Halaman Pengajuan Judul

\section{Halaman Pendaftaran Seminar}

Apabila memilih menu pendaftaran seminar maka akan tampil jumlah mahasiswa yang telah mendaftar seminar dan dapat dipilih sesuai jurusan

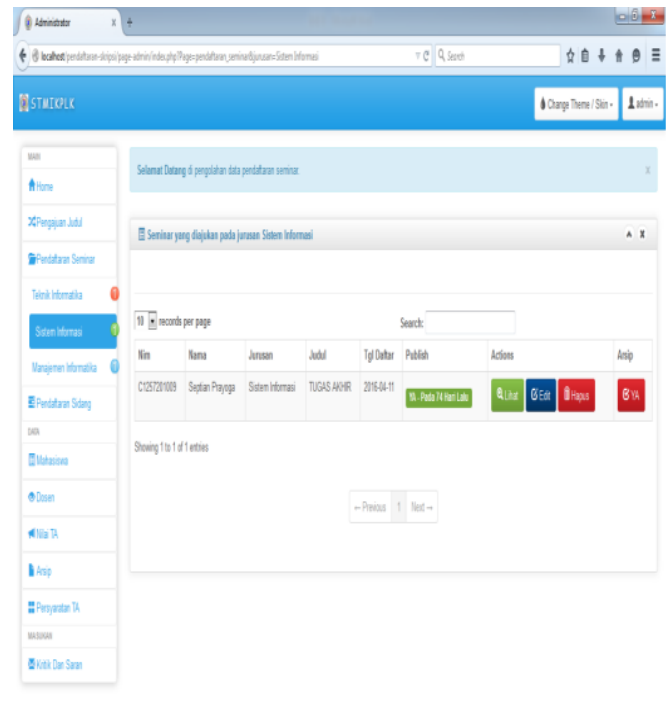

Gambar 4. Pendaftaran Seminar

5. Halaman Pendaftaran Sidang Tugas Akhir

Apabila memilih menu pendaftaran sidang maka akan tampil jumlah mahasiwa yang telah mendaftar sidang dan dapat dipilih sesuai jurusan.

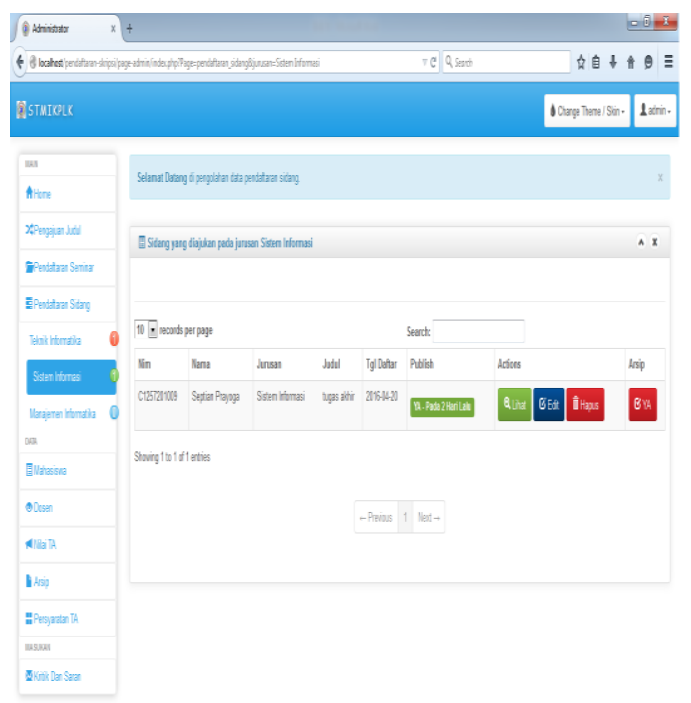

Gambar 5. Pendaftaran Sidang TA

6. Halaman Data Mahasiswa 


$$
\begin{array}{c|l}
\text { Jurnal Sains Komputer dan Teknologi lnformasi } & \text { Page } \\
\text { e-issn: 2655-7460. Volume i No.2, Mei 2019 } & 31-37
\end{array}
$$

Ketika menu mahasiswa di klik maka akan tampil halaman untuk menambah data mahasiswa yang dapat mengajukan judul.

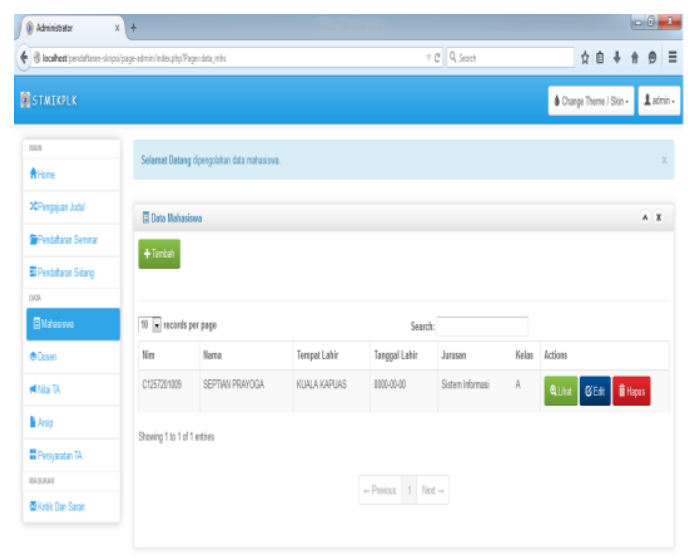

Gambar 6. Data Mahasiswa

\section{Halaman Data Dosen}

Ketika menu dosen di klik maka akan tampil halaman untuk menambah data dosen yang dapat menjadi pembimbing

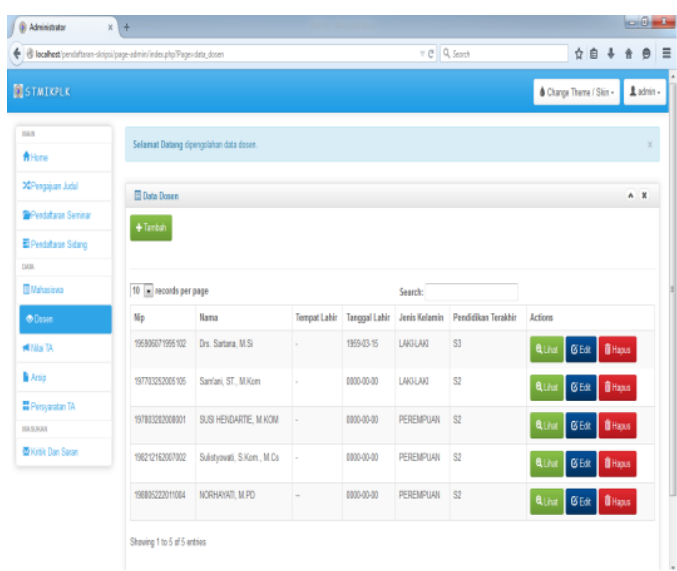

\section{Gambar 7. Data Dosen}

\section{Halaman Data Nilai}

Ketika menu nilai di klik maka akan tampil halaman untuk menambah data nilai mahasiswa.

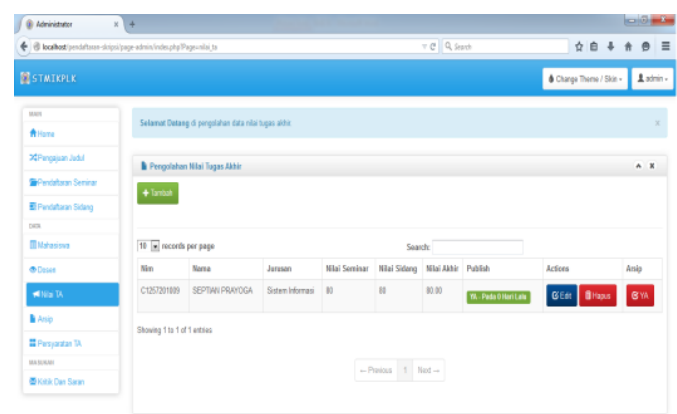

Gambar 8. Data Nilai

9. Halaman Data Arsip

Ketika menu arsip di klik maka akan tampil halaman arsip yang menyimpan data dari judul, proposal, Penelitian, dan nilai mahasiswa.

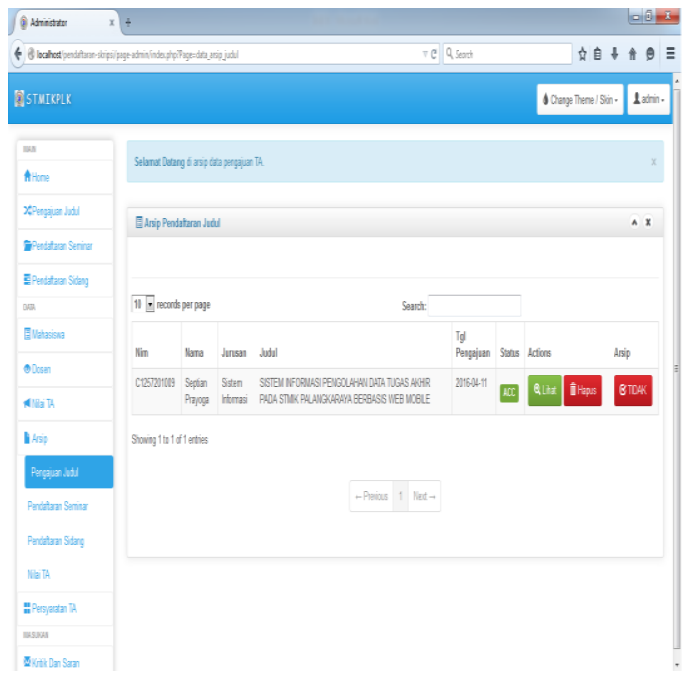

Gambar 9. Data Arsip

10. Halaman Data Persyaratan

Ketika menu persyaratan di klik maka akan tampil halaman persyaratan yang harus di lengkapi oleh mahasiswa ketika ingin melakukan pengajuan judul, pendaftaran seminar proposal, dan sidang Penelitian.

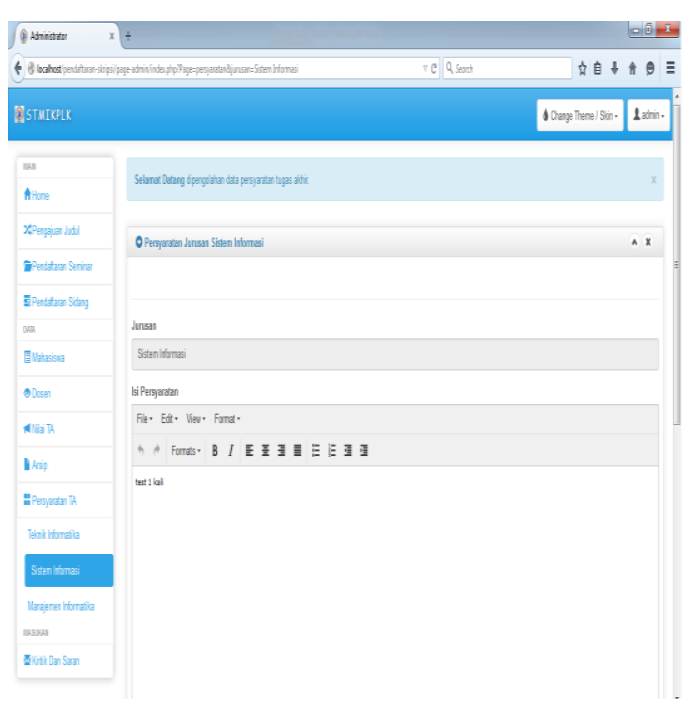

Gambar 10. Data Persyaratan

11. Halaman Menu Kritik dan Saran 
Palangkaraya Berbasis Web Mobile

Ketika menu kritik dan saran di klik maka akan tampil halaman kritik dan saran yang telah di isi oleh user.

\section{KESIMPULAN}

Dapat diambil beberapa kesimpulan yakni:

1. Dalam pengembangan pembuatan aplikasi ini penulis melakukan tahap-tahap sebagai berikut:

a) Perencanaan aplikasi yang akan dibuat.

b) Analisis sistem tahap ini yaitu menganalisis untuk menemukan kelemahan-kelemahannya sehingga dapat diperbaiki.

c) Perancangan Design tahap ini mentranslasi kebutuhan perangkat lunak agar dapat diimplementasikan menjadi program pada tahap selanjutnya.

d) Implementasi Coding merupakan proses coding dan pengujian program secara keseluruhan.

2. Dengan adanya Sistem Informasi Tugas Akhir Mahasiswa pada Program Studi STMIK Palangkaraya ini, diharapkan dapat membantu program studi STMIK Palangkaraya dalam pengumpulan data Tugas Akhir dan untuk mahasiswa yang ingin mendaftar tugas akhir, seminar propoal, sidang skripi secara cepat dan akurat. Pengumpulan data dengan menggunakan aplikasi ini juga tidak banyak memakan biaya dan waktu karena dapat menjangkau Pendaftaran Tugas Akhir yang berada di luar kota Palangkaraya.

\section{DAFTAR PUSTAKA}

Al Fatta, Hanif. 2007. Analisis dan Perancangan Sistem Informasi. Yogyakarta : ANDI.

Andi. 2013. Pengembangan Aplikasi Web Mobile. Setia Kawan Perss, Jakarta.

Arief, M.R. 2011. Pemrograman Web Dinamis Menggunakan PHP Dan Mysql,Andi, Yogyakarta.

Guritno, dkk, 2011, theory and application of IT Research, Andi Yogyakarta, Yogyakarta.

Hidayat, Rahmat.2010. Cara Praktis Membangun Website Gratis, PT Elex Media Komputindo, Jakarta.

Jogiyanto. 2010 Analisis \& Desain Sistem Informasi : Pendekatan Terstruktur,
Teori dan Praktik Aplikasi Bisnis. C.V Andi Offiset, Yogyakarta.

Qamaruzzaman, M. H. 2018. Sistem Informasi Berbasis Mobile Benda-Benda Tradisional Pada Museum Balanga Palangkaraya. Jurnal Sains Komputer dan Teknologi Informasi. Vol 1 Issue 1 eISSN 2655-7460.

https://doi.org/10.33084/jsakti.v1i1.455.

Ridha, H. 2007. Implementasi Twiter Bootstrap Pada ilmukomputer.com. diakses 17 Februari 2017.

Riyanto.2010. Membua tSistem Informasi Penjualandengan PHP dan MySQL.Grafa Media, Yogyakarta.

Sommerville, Ian, 2003. Software Engineering (Rekayasa Perangkat Lunak), Lancaster.

Suardika. 2012. Step by Step Desain Proyek Menggunakan UML, Andi Offset, Yogyakarta.

WahanaKomputer. 2010. Panduan Praktis Menguasai Pemrograman Web dengan JavaScript, Yogyakarta dan Semarang.

Wahyono. Teguh. 2010. Sistem Informasi Konsep Dasar, Analisis Desain dan Implementasi, Graha Ilmu, Yogyakarta. 